\title{
An Analysis on Factors that Affect Academic Achievement in Globalized Environment
}

\author{
Bomi SON $^{1}$, Yooncheong $\mathrm{CHO}^{2}$
}

Received: May 11, 2020. Revised: May 26, 2020. Accepted: June 05, 2020

\begin{abstract}
Purpose: The purpose of this study is to examine the factors affecting the academic achievement of international students in degree programs in global education environment. Based on exploratory research, this study proposed four factors and examined effects of academic factors on academic satisfaction, effects of social factors on social adjustment, effects of cultural factors on cultural adaption, effects of economic factors on financial stability, and effects of four factors on academic achievement of international students. Research design, data, and methodology: This study conducted online survey to collect the data and results provide importance to increase interactivity between international students and teachers and between international students and hosting country's students. Results: The results of this study found what variables affect four proposed factors, while academic satisfaction significantly affects academic achievement rather than other factors. Conclusions: The results show how to improve academic related variables is key for the success of academic achievement. Results of this study provide implications which aspects should be considered to increase overall academic achievement by managing and improving the quality of higher education in global setting. This study provides managerial and policy implications for enhanced academic achievement of international students in global context.
\end{abstract}

Keywords: Academic Achievement, Globalized Environment, Management

JEL Classification Code: F64, M19, A29.

\section{Introduction}

How to provide higher education in global environment has been discussed with perspectives such as global citizenship (Boni \& Calabuig, 2017; Lilley, Barker, \& Harris, 2017) and global competency (Jooste \& Heleta, 2017). While the trend of international student mobility has been "East to West", the trend has become more multidirectional in recent years (Karzunina, West, Moran, \& Philippou, 2017). Asian countries have also become country of origins disseminating students worldwide, as they are now emerging as hosting countries for academic pursuits.

1 Graduate, KDI School of Public Policy and Management, Korea. Email: bomialiciason0710@gmail.com

2 Corresponding Author: Professor, KDI School of Public Policy and Management, Korea. Email: ycho@kdischool.ac.kr

(c) Copyright: The Author(s)

This is an Open Access article distributed under the terms of the Creative Commons Attribution Non-Commercial License (https://creativecommons.org/licenses/by-nc/4.0/) which permits unrestricted non-commercial use, distribution, and reproduction in any medium, provided the original work is properly cited.
In particular, recent statistic from the University of Oxford (2017) shows that the rate of Asian students studying in ASEAN countries increased from $26 \%$ to $42 \%$ during nine years. In the case of Korea, international students in both degree and non-degree programs have increased from 83,842 in 2010 to 142,205 in 2018 (The Ministry of Education and the Korean Educational Development Institute, 2018). The numbers grow due to increased interests in Korea and related studies caused by reasons such as Korean wave and the strategic policy of the Korean government to attract international students (Oh, 2014).

The effects of study abroad are classified as follows: i) effects on international students; ii) effects on hosting countries; and iii) other effects such as foreign affairs. First, the effects on international students include academic experience, cultural experience, social experience, and benefits to future careers. Previous studies (Alharbi \& Smith, 2018; Ha, Lee, \& Shin, 2015) state economic and cultural benefits to the hosting country. Further, Ro, Lee, and Yoo (2003) stated that domestic students are likely to become 
interested in the language, culture, arts, society, and economy of other countries through interaction with international students, and thus will have the opportunity to develop a more global mindset. Ro, Lee, and Yoo (2003) indicated that international students' deep understanding of the society, economy, and culture of their host country has a positive impact on securing support for the hosting country. Nye (2004) stated that the educational exchange is likely to have soft power that makes others desire the same outcomes by co-opting rather than coercing them.

Among the various effects, the purpose of this study is to explore effects of academic achievement of international students in Korea by investigating the factors influencing the academic achievement of students studying abroad. This study also examined effects on hosting countries by examining cultural factors. The results of this study provide managerial and policy implications to improve overall academic achievement for international students in global education environment, while studies on effects on foreign affairs might be the issue for future research. Research questions include as follows: i) how do academic factors affect the academic satisfaction of international students? ii) how do social factors affect the social adjustment of international students? iii) how do cultural factors affect the cultural adaptation of international students? iv) how do economic factors affect the economic stability of international students? v) how do academic satisfaction, social adjustment, cultural adaptation, and financial stability affect the academic achievement of international students?

\section{Literature Review}

Issues of higher education in global environment have been widely examined, while how international students adjust socially, culturally, and economically should be more investigated in addition to academic related aspects. Previous studies (Eze \& Inegbedion, 2015; Lee, 2014; Li, Chen, \& Duanmu, 2010; Martirosyan, Hwang, \& Wanjohi, 2015) have addressed that international students often face difficulties that include, i) lack of language proficiency especially in English-speaking countries; ii) academic conditions such as courses, teaching and assessment methods, unfamiliar academic systems, and communications (Joo, Chung, Lee, \& Han, 2011; Ko \& Chung, 2014; Tamaoka, Ninomiya, \& Nakaya, 2013) iii) social issues associated with various kinds of relationships and living environments in the host societies (Alharbi \& Smith, 2018, Lee, 2014); iv) cultural issues such as culture shock in their adaptation process to the local culture (Lee, 2014; Wang, 2004); v) financial problems based on expensive living expenses or unstable funding resources (Banjong, 2015; Lee, 2017); and vi) psychological problems from homesickness or loneliness (Alsahafi \& Shin, 2017; Banjong, 2015; Sandhu \& Asrabadi, 1994). Additionally, Wan, Chapman, and Biggs (1992) acknowledged that the psychological problems such as stress the students gain from their academic experiences can negatively impact students' academic achievement and satisfaction with the experiences in cultural exchange.

\subsection{Academic Factors}

Academic factors are the factors related to the school and learning environment such as curriculum, courses, school system, and academic supervisor. Ko and Chung (2014) examined the relationship between quality of class, students' satisfaction, and academic performance of the students and found that there were correlation between class quality and students' satisfaction and between class quality and the students' academic performance. Joo, Chung, Lee, and Han (2011) confirmed that the usefulness of the education contents is correlated with academic performance of the students. Tamaoka, Ninomiya, and Nakaya (2013) studied on the factors influencing the satisfaction of the international students in Japanese universities through the survey method and identified that suitability of curriculum is a main factor affecting the satisfaction of international students studying in Japan.

Eze and Inegbedion (2015) pointed out the academic culture and system of the host country as a significant factor that affects international students' academic performance. In particular, some international students were found to be lacking in their ability to deal with a certain education technology that their local counterparts were familiar with, so they have to struggle with the local technology to maintain their studying (Habib, Johannesen, \& Øgrim, 2014). Banjong (2015) also acknowledged that foreign students, especially students from developing countries, are struggling with unaccustomed technologies used at school such as how to use the online bulletin board, download class materials from the website, or do assignments. In the study of Kang, Kim, and Shin (2014), the difficulties faced by many international students were that they did not receive important notifications such as course registration and dormitory arrangement from the administration office. Wimshurst, Bates, and Wortley (2006) reported that it is helpful for the international students that the school communicate better with students about the evaluation methods or the administrative procedures of the university.

\subsection{Social Factors}

Social factors refer to the factors related to social adjustments such as living environment, social activities, and interpersonal relationships. Kim and Auh (2015) found 
that online or offline meetings with local communities help international students to adapt the school easily by obtaining various information. Tamaoka, Ninomiya, and Nakaya (2003) addressed that having good friends help improve their adaptation in the local society. Turley and Wodtke (2010) addressed that the type of residence during college years have no significant effect on 1st-year academic grade for most students. Previous studies (Araujo \& Murray, 2010) also addressed the effect of living environment to student performance. For the impact of extracurricular activity, Correa, Dumas, Jones, Mbarika, and Ong'oa, (2015) found that major-related activities help improve students' academic performance. Strapp and Farr (2010) also affirmed that joining in major-related extracurricular activities gives satisfaction to the students and contributes to their academic achievements.

\subsection{Cultural Factors}

Cultural Factors include familiarity of local culture and local language. Li, Chen, and Duanmu (2010) studied the determinants of low performance among international students in the British universities and observed that the lack of English was an important explanatory variable. Martirosyan, Hwang, and Wanjohi (2015) also argued that there was a correlation between English language skills of international students and their GPAs. Previous studies (Kim, Jun, \& Lee, 1997; Kwon, 2008; Lee, 2014) showed that local language skills influence international students' academic adjustment. Lee (2014) recognized that the limitation of language skills makes it difficult for international students to adapt to the university. According to Kim, Jun, and Lee (1997), level of education, income, Korean language ability, intercultural communication experience, and duration of stay are the significant variables affecting foreigners' adaptation to Korea, but language ability is the most important variable among them. Kwon (2008) also pointed out that local language acquisition substantially affects the academic adjustment of international students. Wang (2004) found that difference in class culture between home country and the U.S. is a stress factor that makes it tough for international students to adapt to school. Lee (2014) addressed that international students have difficulties in adapting to the hierarchical culture that exists in the Korean society.

\subsection{Economic Factors}

Regarding economic factors affecting international students, Lee (2017) observed that international students who are not in a financially stable condition are suffering from coping with the concerns regarding tuition and living expenses. Banjong (2015) also found that financial pressure among international students is related to the poor academic performance. Beblo and Lauer (2004), however, analyzed the relationship between economic change and educational achievement and addressed the financial resources such as parents' wealth or income were very slightly related to the educational achievement of their children.

Having a job also influences the academic achievement of international students in a negative way. A study of Tamaoka, Ninomiya, and Nakaya (2003) showed that parttime work hurts international students' satisfaction with university life and this might be because the work reduces time to concentrate on their study or research. $\mathrm{Li}$ and Grineva (2016) affirmed that there is a direct correlation between the academic performance of refugee students who work and study simultaneously to support their family.

\subsection{Other Factors}

Besides social, academic, cultural and economic factors, some other factors in terms of their personal traits, attitudes or backgrounds are found to affect the foreign students' academic performance. Ren and Hagedorn (2012) suggested some innate characteristics of international students as significant factors; in particular, the region of origin were significantly related to international graduate students' GPA at the master's level as well as gender and age. Wimshurst, Bates, and Wortley (2006) stated that gender affects the academic performance; female students gain better grades than male students. Jochems, Snippe, Smid, and Verweij (1996) argued that the academic success depends entirely on the student's ability and effort. Stoynoff (1997) addressed that a student with the motivation and ability to get up-todate information on the assignment appeared to gain better grades in school. In a study of Li, Chen, and Duanmu (2010), perception of the students studying abroad on the importance of their academic success to family was found to significantly affect their academic achievement, but in a negative way.

\section{Theoretical Background}

New Institutionalism refers to the position that considers institution as an independent variable equal to a person or higher than a person by influencing human behavior in explaining all phenomena in society such as politics, economy, and administration; and dynamically describes causal relationships between institutions and institutions; institutions and individuals, institutions and policies (Yoo, 2012). From the view of the new institutionalism, institutions restrict human behaviors and behaviors of each individual in the institutional context have patterns of regularity; thus, the new institutionalism focuses on the 
individual actions that take place in the context of institutions (Ha, 2002). Student integration theory by Tinto (1993) is the most widely applied theory and addresses social and academic integration. Further, Maslow (1943)'s theory that discusses human's common desire and hierarchized needs supports the proposed model of this study. Herzberg (1964)' motivators such as achievement and opportunity and hygiene factors such as benefits and monetary factors that gives satisfaction also support proposed factors of this study.

\section{Hypotheses Development}

This study developed hypotheses by modifying previous studies on international students. Based on literature reviews, this study applied four key factors and the effects on academic achievement. Additional effects besides four proposed factors such as demographics and region of origin were also analyzed.

\subsection{Effects of Academic Variables on Academic Satisfaction}

This study proposed effects of academic factors on academic satisfaction that refers to a dynamic process involving the interaction between the student-faculty and teaching-learning environment (Chen, Farmer, Barber, \& Wayman, 2012, p.370). Chung and Hwang (2004) mentioned that learning environment, learning contents, and teachers are found to significantly affect academic satisfaction. Alsahafi and Shin (2017) indicated that international students have difficulties in academic adjustment due to the assessment tools, particularly oral presentations. For the relationships with academic advisors, Herbert (2006) supported that the rate of learners' satisfaction is low when interaction with faculty is infrequent. Lee (2014) pointed out that features of the school system such as the examination system, announcement, and credit completion system are set up for domestic students, which impedes the academic adaptation of foreign students. Dean (2012) also found that foreign students having difficulty understanding how the school administration system works, which challenges their academic success. Previous studies indicated the problem of school services for international students. Based on the consideration above, this study classified academic variables that might affect academic satisfaction including diversity of courses, teaching methodology, local school system, relationship with an academic advisor, and sharing information. The study hypothesized that academic variables affect academic satisfaction of international students.
H1a: International students' perception of the diversity of courses affects their academic satisfaction.

H1b: International students' perception of teaching methodology affects their academic satisfaction.

H1c: International students' perception of the school system affects their academic satisfaction.

H1d: International students' perception of their relationship with academic advisors affects their academic satisfaction.

H1e: International students' perception of information sharing of school affects their academic satisfaction.

\subsection{Effects of Social Variables on Social Adjustment}

This study posits that effects of social factors that are associated with international students' adjustment to the host society such as any kinds of relationship with local people and living environment affect social adjustment. Gerdes and Mallinckrodt (1994) addressed that social adjustment is a significant factor for students to adapt to college life successfully without dropping out. Previous studies indicated that a limited relationship with the students in a host country negatively influences the adjustment of international students (Alsahafi \& Shin, 2017; Kim, Kim, \& Kang, 2007). Kim, Jun, and Lee (1997) found that the frequency of communication with local people positively affects the level of cultural adaptation and social adjustment of international students. According to Tinto (1997), joining collaborative learning groups allows students to form a supportive network that contributes to bonding students to the broader school community and school life. The existence of a student buddy system has a decisive effect on strengthening the social presence of the students and team building, and also positively affecting student satisfaction and persistence (Motzo, 2016). Ismail and Jui (2014) showed that communication and supports through a mentoring program is significant for mentees' academic performance.

Previous studies stated living conditions and extraactivity. Araujo and Murray (2010) estimated the influences of living in a dormitory on the academic achievement of the college students and found that living on campus substantially improved the students' grades. Regarding the effect of extracurricular activities, Kim (2007) identified that participation in club activities had a buffering effect when lack of understanding in the culture. Shin, Shin, and Jung (2008) showed that extracurricular activities have a negative impact on students' grades. This study proposed variables that might affect social adjustment of including relationships with local friends, having a mentor or buddy, residence type, and extracurricular activity and hypothesized the effect of those variables on the social adjustment. 
H2a: International students perception of their relationships with local friends affects their social adjustment.

H2b: International students' perception of a mentor or buddy affects their social adjustment.

H2c: International students' perception of residence type affects their social adjustment.

H2d: International students' perception of extracurricular activities affects their social adjustment.

\subsection{Effects of Cultural Variables on Cultural Adaptation}

This study proposed that effects of cultural factors on cultural adaptation. Language skills were pointed out as a factor affecting the adaptation of foreigners in a host country in many studies. While some researchers mention language skills as academic or social factors (Lebcir, Wells, \& Bond, 2008), this study regards language skills as a cultural factor as a reflection of culture (Wierzbicka, 1986). Regarding cultural interest and adaptation, Kim and Lee (2014) investigated the relationship between interest in other countries and multicultural acceptance. Lee, Ahn, and Lee (2013) also examined that acceptance of multiculturalism rises as the amount of multicultural content viewed is higher, especially in terms of assertiveness and openness and this result implies that people become more receptive to other cultures. This study proposed variables that might affect cultural adaptation including local language skills, preinterest in the local culture, and receptiveness to the local culture and hypothesized the effect of those variables on the cultural adaptation.

H3a: International students' perception of local language skills affects their cultural adaptation.

H3b: International students' pre-interest in the local culture affects their cultural adaptation.

H3c: International students' receptiveness to the local culture affects their cultural adaptation.

\subsection{Effects of Economic Variables on Financial Stability}

This study proposed that effects of economic factors on financial stability. Ganem and Manasse (2011) argued that students receiving merit-based scholarships are likely to outperform and this result implies that scholarship increases the possibility of academic success by making students more motivated. Besides tuition fees, it was found that a significant number of students in higher education are concerned about the extent of their living expenses and debt related to their degrees, and undergraduates in particular are worried more about living costs than tuition (Universities
UK, 2018). Lee (2017) stated that international students who are privately funded are economically unstable and struggle to balance their study and part-time jobs. Kang, Kim, and Shin (2014) examined that having a part-time job is a significant factor that causes stress for international students. This study proposes that having a job might have a positive impact on student's financial stability with reduced economic concern. This study proposed variables that might affect the financial stability of the students, including tuition fees, living expenses, and having a job and hypothesized the effect of those variables on the on the financial stability.

H4a: International students' perception of tuition fees affects their financial stability.

H4b: International students' perception of living expenses affects their financial stability.

H4c: International students' perception of having a job affects their financial stability.

\subsection{Effects on Academic Achievement}

Eze and Inegbedion (2015) observed that most international students have issues in adapting to a new environment in a hosting country, and those problems negatively affect their academic achievement. Kim (2007) contended that lack of understanding the host culture constrains the academic achievement of international students. It was also observed that a great gap in culture between the home country and the host country had a significant impact on the behavior and academic achievement of international students (Eze \& Inegbedion, 2015). Based on the findings of the previous studies, this study hypothesized that the level of academic satisfaction, social adjustment, cultural adaptation, and financial stability of international students respectively affect academic achievement.

H5: Academic satisfaction level of international students affects their academic achievement

H6: Social adjustment level of international students affect their academic achievement

H7: Cultural adaptation level of international students affect their academic achievement

H8: Financial stability level of international students affect their academic achievement

\section{Methodology}

This study conducted an online survey through the online platform to help distribute a questionnaire and collect data. The survey was developed in English and distributed to educational environments have taught in English. Survey 
items were developed based on the exploratory researches of previous studies. The previous studies of international students in Korea are mainly limited to students from specific country, or to a specific major or a university, so those results are hard to generalize. To overcome the limitations of previous studies, this survey distributed to universities with diverse nationalities, regardless of nationality or major. This study collected data from international students in higher education, including Bachelor, Master, and Ph.D. programs. In this context, the survey was distributed to 200 international students attending degree programs in 23 different universities across South Korea via email and SNS, and 133 respondents completed the survey with the response rate of $66.5 \%$.

The questionnaire consisted of 57 questions asking about opinions about proposed variables. The questionnaire was divided into the following parts: warm-up questions, academic factors, social factors, cultural factors, economic factors, academic achievement, and demographic questions. The respondents were asked to answer the questions about their degree program, university, length of study abroad, major, and academic performance in Part 1. Parts 2 5 comprised questions on the perceptions and experiences regarding factors including academic, social, cultural, economic, and academic achievement. The last part of the survey consisted of demographic questions about gender, age, and country of origin. The survey adopted a 5-point Likert scale in which 1 indicates strongly disagree and 5 indicates strongly agree.

\section{Data Analysis}

Among 133 respondents, $61.07 \%$ were male and $38.93 \%$ were female. Regarding the age distribution of the respondents, $24.43 \%$ were $19-24$ years old, $54.96 \%$ were 25 29 years old, $14.50 \%$ were $30-34$ years old, $3.05 \%$ were 35 39 years old, and $2.29 \%$ of the respondents were more than 40 years old.

In terms of region of origin, the students from Asia were $77.10 \%$ with the highest number of respondents, $10.69 \%$ were from sub-Saharan Africa, 4.58\% were from Europe, 3.05\% from Middle East, North Africa, and Greater Arabia, 2.29\% from South America, 0.76\% from Central America and the Caribbean, and $1.53 \%$ were from places. In terms of marital status, $16.15 \%$ of the respondents were married and $83.85 \%$ were single. With regards to degree programs of the respondents, $14.29 \%$ were in Bachelor's programs, $59.40 \%$ were in Master's programs, and $26.32 \%$ were Ph.D. candidates. In terms of major, respondents were in degree program with diverse fields of major, including humanities, social sciences, natural sciences, engineering, arts, etc. Regarding the institutions of the respondents, the respondents are affiliated at 23 different higher educational institutions.

Table 1: Summary of Demographic Variables

\begin{tabular}{|c|c|c|}
\hline \multicolumn{2}{|r|}{ Variable } & \multirow{2}{*}{$\begin{array}{c}\% \\
61.07 \%\end{array}$} \\
\hline \multirow{2}{*}{ Gender } & Male & \\
\hline & Female & $38.93 \%$ \\
\hline \multirow{5}{*}{ Age } & $19-24$ & $24.43 \%$ \\
\hline & $25-29$ & $54.96 \%$ \\
\hline & $30-34$ & $14.50 \%$ \\
\hline & $35-39$ & $3.05 \%$ \\
\hline & $40-$ & $2.29 \%$ \\
\hline \multirow{9}{*}{ Region } & Asia & $77.10 \%$ \\
\hline & $\begin{array}{c}\text { Middle East, North Africa, \& } \\
\text { Greater Arabia }\end{array}$ & $3.05 \%$ \\
\hline & Sub-Saharan Africa & $10.69 \%$ \\
\hline & Europe & $4.58 \%$ \\
\hline & Australia and Oceania & $0.00 \%$ \\
\hline & North America & $0.00 \%$ \\
\hline & $\begin{array}{c}\text { Central America and the } \\
\text { Caribbean }\end{array}$ & $0.76 \%$ \\
\hline & South America & $2.29 \%$ \\
\hline & Others & $1.53 \%$ \\
\hline \multirow{2}{*}{ Marital status } & Married & $16.15 \%$ \\
\hline & Single & $83.85 \%$ \\
\hline \multirow{3}{*}{$\begin{array}{l}\text { Degree } \\
\text { Program }\end{array}$} & Bachelor & $14.29 \%$ \\
\hline & Master & $59.40 \%$ \\
\hline & Ph.D. & $26.32 \%$ \\
\hline
\end{tabular}

\subsection{Hypotheses Testing}

Regression analyses were conducted to test the hypotheses of this study. Table 2 shows the regression analysis results for the effects of the academic variables on academic satisfaction of the international students. The results demonstrated that overall, the model is statistically significant at 0.01 level with $\mathrm{F}=48.739$ ( $\mathrm{r}$-square $=.685)$, indicating that academic variables affects academic satisfaction. Among variables, diversity of courses, school system, and sharing information of school are found to be significantly affect academic satisfaction, while strengths of effects showed significant for sharing information of school, school system, and diversity of courses by orders. This study found that teaching methodology and relationship with academic advisor did not show significant on academic satisfaction. 
Table 2: Effects of Academic Variables on Academic Satisfaction

\begin{tabular}{|c|c|c|c|c|}
\hline Factor & $\begin{array}{c}\text { B } \\
\text { (Std.Error) }\end{array}$ & $\boldsymbol{\beta}$ & $\mathbf{T}$ & Sig. \\
\hline $\begin{array}{c}\text { Diversity of } \\
\text { courses }\end{array}$ & $\begin{array}{c}0.161 \\
(0.061)\end{array}$ & 0.163 & 2.629 & $* *$ \\
\hline $\begin{array}{c}\text { Teaching } \\
\text { methodology }\end{array}$ & $\begin{array}{c}0.056 \\
(0.076)\end{array}$ & 0.055 & 0.733 & \\
\hline School system & $\begin{array}{c}0.375 \\
(0.085)\end{array}$ & 0.340 & 4.430 & $* * *$ \\
\hline $\begin{array}{c}\text { Relationship with } \\
\text { academic advisor }\end{array}$ & $\begin{array}{c}-0.021 \\
(0.064)\end{array}$ & -0.022 & -0.332 & \\
\hline $\begin{array}{c}\text { Sharing } \\
\text { information }\end{array}$ & $\begin{array}{c}0.438 \\
(0.066)\end{array}$ & 0.465 & 6.614 & $* * *$ \\
\hline R-squared & & & & .685 \\
\hline
\end{tabular}

** Significant at $p<0.05 ;{ }^{* * *}$ Significant at $p<0.01$

Table 3 shows regression analysis for the effect of the social variables on social adjustment. The results found that overall, the model significant at 0.01 level with $\mathrm{F}=6.073$ (rsquare $=.432$ ). These results indicate that social variables affect social adjustment of international students. Among the social variables, the results found that relationship with local friends and extracurricular activity significantly affected the social adjustment level, while having a mentor or buddy and residence type did not show significant on social adjustment. Among significant variables, effects of extracurricular activity on social adjustment was stronger than effects of relationship with local friends.

Table 3: Effects of Social Variables on Social Adjustment

\begin{tabular}{|c|c|c|c|c|}
\hline Factor & $\begin{array}{c}\text { B } \\
\text { (Std. Error) }\end{array}$ & $\beta$ & $\mathbf{T}$ & Sig. \\
\hline $\begin{array}{l}\text { Relationship with } \\
\text { local friends }\end{array}$ & $\begin{array}{c}0.317 \\
(0.149)\end{array}$ & 0.333 & 2.127 & ** \\
\hline $\begin{array}{l}\text { Having a mentor } \\
\text { or buddy }\end{array}$ & $\begin{array}{c}0.083 \\
(0.140)\end{array}$ & 0.081 & 0.593 & \\
\hline Residence type & $\begin{array}{l}-0.081 \\
(0.149)\end{array}$ & -0.077 & -0.542 & \\
\hline $\begin{array}{l}\text { Extracurricular } \\
\text { activity }\end{array}$ & $\begin{array}{c}0.407 \\
(0.152)\end{array}$ & 0.427 & 2.684 & ** \\
\hline R-squared & & & & .432 \\
\hline
\end{tabular}

This study also examined the effect of cultural variables on cultural adaptation. The regression analysis results in Table 4 indicated that overall, the models were significant at .00 level with $\mathrm{F}=18.973$ (r-square $=.309$ ). Thus, the results found that cultural adaptation is affected by cultural variables. Specifically, cultural adaptation level is found to be significantly related to local language skills and receptiveness of the local culture, while effects of receptiveness of the local culture on cultural adaption was stronger than effects of local language skills.

Table 4: Effects of Cultural Variables on Cultural Adaptation

\begin{tabular}{|c|c|c|c|c|}
\hline Factor & $\begin{array}{c}\text { B } \\
\text { (Std. Error) }\end{array}$ & $\boldsymbol{\beta}$ & $\mathbf{T}$ & Sig. \\
\hline $\begin{array}{c}\text { Local language } \\
\text { skills }\end{array}$ & $\begin{array}{c}0.133 \\
(0.057)\end{array}$ & 0.173 & 2.305 & $* *$ \\
\hline $\begin{array}{c}\text { Pre-interest in the } \\
\text { local culture }\end{array}$ & $\begin{array}{c}0.070 \\
(0.056)\end{array}$ & 0.098 & 1.245 & \\
\hline $\begin{array}{c}\text { Receptiveness of } \\
\text { the local culture }\end{array}$ & $\begin{array}{c}0.493 \\
(0.078)\end{array}$ & 0.495 & 6.330 & $* * *$ \\
\hline R-squared & & & & .309 \\
\hline
\end{tabular}

** Significant at $p<0.05 ;{ }^{* * *}$ Significant at $p<0.01$

Table 5: Effects of Economic Variables on Financial Stability

\begin{tabular}{|c|c|c|c|c|}
\hline Factor & $\begin{array}{c}\text { B } \\
\text { (Std. Error) }\end{array}$ & $\boldsymbol{\beta}$ & $\mathbf{T}$ & Sig. \\
\hline Tuition fee & $\begin{array}{c}-0.445 \\
(0.168)\end{array}$ & -0.605 & -2.645 & $* *$ \\
\hline Living expenses & $\begin{array}{c}0.369 \\
(0.169)\end{array}$ & 0.499 & 2.182 & $* *$ \\
\hline Having a job & $\begin{array}{c}0.547 \\
(0.300)\end{array}$ & 0.358 & 1.827 & \\
\hline R-squared & & & & .467 \\
\hline
\end{tabular}

** Significant at $p<0.05 ;{ }^{* * *}$ Significant at $p<0.01$

For the effect of economic variables on financial stability, the results of regression analysis found that overall, the models significant at 0.05 level with $F=4.085$ (r-square $=.467$ ). As shown in Table 5, tuition fees and living expenses significantly affected financial stability. Table 6 shows that the results of the regression analysis of H5, H6, $\mathrm{H} 7$, and $\mathrm{H8}$. The results found that overall, the models significant at 0.01 level with $\mathrm{F}=7.510$ (r-square $=.193$ ). However, results showed that effects of academic satisfaction on academic achievement were significant, while other factors were not significant. Based on the findings, H5 was significantly accepted.

Table 6: Effects on Academic Achievement

\begin{tabular}{|c|c|c|c|c|}
\hline Factor & $\begin{array}{c}\text { B } \\
\text { (Std. Error) }\end{array}$ & $\boldsymbol{\beta}$ & $\mathbf{T}$ & Sig. \\
\hline Academic \\
satisfaction & $\begin{array}{c}0.356 \\
(0.087)\end{array}$ & 0.374 & 4.067 & $* * *$ \\
\hline Social adjustment & $\begin{array}{c}0.121 \\
(0.104)\end{array}$ & 0.122 & 1.158 & \\
\hline Cultural adaptation & $\begin{array}{c}-0.202 \\
(0.117)\end{array}$ & -0.173 & -1.729 & \\
\hline Financial stability & $\begin{array}{c}0.137 \\
(0.092)\end{array}$ & 0.129 & 1.486 & \\
\hline R-squared & & & & .193 \\
\hline
\end{tabular}

** Significant at $p<0.05 ;{ }^{* * *}$ Significant at $p<0.01$ 


\section{Conclusion}

\subsection{Findings}

This study investigated the factors affecting the academic achievement of international students' degree programs in global context. As international students are an increasing in higher education, the academic achievement of international students has become an important issue. Studying abroad should be consistently encouraged since it provides quality education and benefits for future careers to the students, and economic and cultural benefits to the host country also contribute to promotion of exchange and understanding among countries. The results of this study found that diversity of courses, school system, and sharing information of school significantly affected academic satisfaction of international students, while teaching methodology and relationship to academic advisors did not show significance on academic satisfaction. This study explains insignificant effects of teaching methodology on academic satisfaction due to the fact that the preferred teaching methods might differ from person to person, as additional survey results showed that $32.58 \%$ of the respondents prefer lecture by professor, $31.82 \%$ answered problem solving and case studies, and $23.48 \%$ of the respondents expressed a preference for active discussion methodology. The results implied the adoption of better teaching methods should be considered to improve academic satisfaction. The results of this study found that relationship with academic advisors do not significantly affect academic satisfaction, while Herbert (2006) argued that that satisfaction of learners is low when there is infrequent interaction with faculty. Therefore, the results might cause due to the lack of interactions with academic advisor.

On the social side, relationship with local friends and extracurricular activity are found to be factors that affect social adjustment of the international students, while having a mentor or buddy and residence type did not significantly affect social adjustment of international students. In the case of having a mentor or buddy, it seems that it was difficult to measure its effect on social adjustment because about $55 \%$ of the respondents did not have such an assigned mentor or buddy. For residence type, the result of this study is different from previous findings (Araujo \& Murray, 2010) by showing that residence type does not affect social adjustment. This might be happened if students usually spend more time in school or outside rather than at residence. Regarding effects of cultural variables, the result showed that pre-interest in the host culture did not show significant effect on cultural adaptation. It might be happened because there are some international students who had never been interested in the host culture, while they became greatly interested in the host culture and adapted to it quickly upon entry. This study found that only academic satisfaction significantly affected academic achievement, while other proposed factors did not show significant on academic achievement.

Additionally, this study applied t-test and ANOVA for the effects based on demographics. The result of $t$-test found that gender has no significant effect on academic achievement of international students. The result of ANOVA found that means of academic satisfaction and cultural adaptation level differ based on the major. ANOVA results also showed that means of academic satisfaction and financial stability differ based on the country of origin. It is probable that the disparity in academic satisfaction is led by the difference between the students who come from countries where academic systems and cultures similar to those of the host country and totally different academic systems from those of the host country. In addition, difference in financial stability seems to be due to the different funding systems or the level of pricing among the countries of origin. It was also identified that levels of social adjustment and cultural adaptation are significantly affected by the number of local friends. Finally, this study found that the level of financial stability differ based on the marital status.

\subsection{Managerial Implication}

This study proposes managerial implications regarding the issues of study abroad. Results of this study provide implications which aspects should be considered to increase overall academic achievement by managing higher education in global setting. As results showed, academic achievement was mainly affected by academic satisfaction rather than other factors. Therefore, how to manage teaching methods to improve academic satisfaction in global environment will be crucial for better academic achievement.

As results show how to improve interactivity between international students and teachers and between international students and local friends are important to enhance academic achievement. The results also provide implication on social and cultural adaptation. As results show, how to improve interactivity between international students and teachers and between international students and hosting country's students are important to enhance academic achievement. In addition to the physical interaction, online interaction through systems regarding course registration, dormitory application, evaluation system, and campus life to share information will be helpful to improve overall academic achievement. This study found the effect of sharing information of school on academic satisfaction was stronger than other factors of academic variables. Development of better management system to integrate information will be helpful in global environment of higher education. 
The results also provide implication how to make international students adapt better in new society and culture. This study confirms that students' local language skills significantly affect their cultural adjustment, thus influencing academic achievement in the end. The survey results show that about $53.44 \%$ of the respondents perceive their local language skills to be poor or very poor. Universities might offer diverse local languages programs, so the international students have more opportunities to learn a local language and effectively adapt to the local culture. It will also help enhance social adjustment as the results show significant effects of extracurricular activity and relationship with local friends by adjusting society. Finally, it is also important to enhance interactions between institutions and international students. When international students face an unfamiliar environment or problem in the host country, it is the university that the student asks for help. However, if there is not enough communication with the school, international students may have difficulties in adapting to general life in the host country, not only to pursing academic achievement. It is also important to provide demand-oriented services and create environment that international students can concentrate on their studies with continuous feedback and strengthen ties.

Additionally, it is recommended for the universities to diversify courses in English for international students. From the survey results of the study, about $45 \%$ of the respondents answered that more than half of the total courses are not offered in English in their universities. If the university does not offer a variety of English courses, international students have limited choices that will cause negative impact on their academic satisfaction, thus lowering academic achievement.

\subsection{Policy Implication}

Several social and cultural issues could be raised that might be caused by the lack of policy. It is necessary to grasp the state of affairs and establish a policy to address the issue at the national level as the numbers of international students and the institutions hosting international students are globally increasing. To ensure the academic success of international students, the government needs to create better academic environment in which those students can adjust well. The government may establish a policy that all universities hosting international students should organize an office dedicated to the better management so that they can help those students properly. Although academic achievement is one of the goals in the host country, it is also necessary for the government to be concerned with the social adjustment and financial stability of international students in order to ensure their emotional stability and quality of life. For instance, local governments are able to enhance communication between international students and the local community and support the international students in practical ways.

\subsection{Future Research and Limitations}

This study has limitations. Future research should increase sample size and collect the answers from more diverse universities. Future study might apply a qualitative research method such as in-depth interviews to draw inner feelings. In this regard, it is recommended to implement both quantitative and qualitative methods in future studies to make it possible to acquire both comprehensive and in-depth results. Lastly, though this study focuses on the factors affecting academic achievement, future study might investigate other issues such as the emotional psychological state rather than achievement.

\section{References}

Alharbi, E. S., \& Smith, A. P. (2018). Review of the Literature on Stress and Wellbeing of International Students in EnglishSpeaking Countries. International Education Studies, 11(6), 22-44.

Alsahafi, N., \& Shin, S. C. (2017). Factors Affecting the Academic and Cultural Adjustment of Saudi International Students in Australian Universities. Journal of International Students, 7(1), 53-72.

Araujo, P., \& Murray. J. (2010). Estimating the Effects of Dormitory Living on Student Performance. Economic Bulletin, 30(1), 866-878.

Banjong, D. N. (2015). International Students' Enhanced Academic Performance: Effects of Campus Resources. Journal of International Students, 5(1), 132-142.

Beblo, M., \& Lauer, C. (2004). Do family resources matter? Educational attainment during transition in Poland. Economics of Transition, 12(3), 537-558.

Boni, A., \& Calabuig, C. (2017). Education for Global Citizenship at Universities: Potentialities of Formal and Informal Learning Spaces to Foster Cosmopolitanism. Journal of Studies in International Education, 21(1), 22-38.

Chen, H. C., Farmer, S., Barber, L., \& Wayman, M. (2012). Development and Psychometric Testing of the Nursing Student Satisfaction Scale. Nursing education perspectives, 33(6), 369-373.

Chung, K. H., \& Hwang, I. H. (2004). The Effects of Determinants of Learning Satisfaction on Overall Service Quality, and Student Satisfaction. Academy of Customer Satisfaction Management, 6(2), 51-74.

Correa, M., Dumas, B. K., Jones, C., Mbarika, V., \& Ong'oa, I. M. (2015). Extracurricular Activities and Academic Achievement: A Literature Review. Global Advanced Research Journal of Educational Research and Review, 4(9), 165-169.

Dean, A. (2012). Improving the Learning Experience for International Students. International Journal of Management Cases, 4(1), 207-222. 
Eze, S. C., \& Inegbedion, H. (2015). Key Factors Influencing Academic Performance of International Students' in UK Universities: A Preliminary Investigation. British Journal of Education, 3(5), 55-68.

Ganem, N. M., \& Manasse, M. (2011). The Relationship between Scholarships and Student Success: An Art and Design Case Study. Education Research International, 1-8.

Gerdes, H., \& Mallinckrodt, B. (1994). Emotional, Social, and Academic Adjustment of College Students: A Longitudinal Study of Retention. Journal of Counseling \& Development, 72(3), 281-288.

Ha, Y. S. (2002). Recent Trends in New Institutionalism: Theoretical Innovations and Convergence. Korean Republic Administration Review, 36(4), 339-359.

Ha, Y. S., Lee, J. H., \& Shin, G. H. (2015). Estimating the Economic Benefits of International Students Recruitment. The Journal of Economics and Finance of Education, 24(3), 89112.

Habib, L., Johannesen, M., \& Øgrim, L. (2014). "Experiences and Challenges of International Students in Technology-Rich Learning Environments." Educational Technology \& Society, 17(2), 196-206.

Herbert, M. (2006). Staying the Course: A Study in Online Student Satisfaction and Retention. Online Journal of Distance Learning Administration, 9(4), 300-317.

Herzberg, F. (1964). The Motivation-Hygiene Concept and Problems of Manpower. Personnel Administration, 27, 3-7.

Ismail, A., \& Jui, M. K. K. (2014). The Role of Mentoring Program in Enhancing Mentees' Academic Performance. Journal of Education and Learning, 8(1), 13-22.

Jochems, W., Snippe, J., Smid, H. J., \& Verweij, A. (1996). The Academic Progress of Foreign Students: Study Achievement and Study Behaviour. Higher Education, 31(3), 325-340.

Joo, Y. J., Chung, A. K., Lee, S. C., \& Han, A. R. (2011). Prediction of Academic Satisfaction and Academic Achievement Variables in Computer Education of Engineering College Class. The Transactions of the Korean Institute of Electrical Engineers, 60(2), 56-62.

Jooste, N., \& Heleta, S. (2017). Global Citizenship versus Globally Competent Graduates: A Critical View from the South. Journal of Studies in International Education, 21(1), 39-51.

Kang, M. K., Kim, M., \& Shin, E. H. (2014). An Integrated Study on Academic Achievement and Adaptation to Life of Foreign Students. The Korean Association of General Education Conference Proceedings, 6, 261-277.

Karzunina, D., West, J., Moran, J., \& Philippou, G. (2017). Student Mobility \& Demographic Changes. London, England: QS Intelligence Unit.

Kim, D. H., Kim, A. Y., \& Kang, E. (2007). The Inquiry of Chinese Graduate Students' Adaptive Experience in Korea: by Grounded Theory Approach. Asian Journal of Education, 8(3), 159-187.

Kim, H. S., \& Lee, S. C. (2014). Measuring Multiculture Acceptance by Skewed Interest in Regions: A Case Study of Dalseo-gu, Korea. The Korea Local Administration Review, 28(1), 89-114.

Kim, H. J., Jun, K. H., \& Lee, H. K. (1997). Assimilation of Foreigners in Korea: Focusing on Intercultural
Communication and Social Networks. Korean Journal of Journalism \& Communication Studies, 40, 105-139.

Kim, J., \& Auh, S. (2015). The Path Analysis of International Students' University-Academic Adjustment and the Academic Seeking Help from the Off-line Community at the Leading Private Universities in Seoul. Korea Education Inquiry, 33(3), 93-116.

Kim, S. N. (2007). A Study on the Determinants of University Adaptation by Foreign Students. Korean Society for Journalism and Communication Studies, 1, 29-46.

Ko, W. H., \& Chung, F. M. (2014). Teaching Quality, Learning Satisfaction, and Academic Performance among Hospitality Students in Taiwan. World Journal of Education, 4(5), 11-20.

Kwon, Y. Y. (2008). A Qualitative Study on International Students' Early Transition into Korean University. The Korea Educational Review, 14(1), 301-333.

Lebcir, R. M., Wells, H., \& Bond, A. (2008). Factors Affecting Academic Performance of International Students in Project Management Courses: A Case Study from a British Post 92 University. International Journal of Project Management, 26(3), 268-274.

Lee, H., Ahn, J., \& Lee, S. (2013). An Empirical Study on the Effect of Multicultural Contents on Multicultural Acceptability. Korean Journal of Journalism \& Communication Studies, 57(3), 34-57.

Lee, J. S. (2017). Challenges of International Students in a Japanese University: Ethnographic Perspectives. Journal of International Students, 7(1), 73-93.

Lee, Y. K. (2014). A Study about Acculturation of amongst Foreign Exchange Student's Korean Culture and Graduate School. Bilingual Research, 55, 249-284.

Li, G., Chen, W., \& Duanmu, J. (2010). Determinants of International Students' Academic Performance: A Comparison between Chinese and Other International Students. Journal of Studies in International Education, 14(4), 389-405.

Li, X., \& Grineva, M. (2016). Academic and Social Adjustment of High School Refugee Youth in Newfoundland. TESL Canada Journal, 34(1), 51-71.

Lilley, K., Barker, M., \& Harris, N. (2017). The Global Citizen Conceptualized: Accommodating Ambiguity. Journal of Studies in International Education, 21(1), 6-21.

Martirosyan, N. M., Hwang, E., \& Wanjohi, R. (2015). Impact of English Proficiency on Academic Performance of International Students. Journal of International Students, 5(1), 60-71.

Maslow, A. H. (1943). A Theory of Human Motivation. Psychological Review, 50(4), 370-396.

Motzo, A. (2016). Evaluating the Effects of a 'Student Buddy' Initiative on Student Engagement and Motivation. In C. Goria, O. Speicher, \& S. Stollhans (Eds), Innovative Language Teaching and Learning at University: Enhancing Participation and Collaboration, 19-28.

Nye, J. S. Jr. (2004). Soft power: The Means to Success in World Politics. New York, NY: Public Affairs.

Oh, J. E. (2014). Analysis on the Actual Condition of the Korean Government Scholarship Foreign Students. IOM MRTC Working Paper Series (No. 2014-03). Goyang, Korea: IOM Migration Research and Training Centre. 
Ren, J., \& Hagedorn, L. S. (2012). International Graduate Students' Academic Performance: What are the influencing factors? Journal of International Students, 2(2), 135-143.

Ro, J. H., Lee, I. Y., \& Yoo, G. H. (2003). University Marketing Strategies by Country and Region for Expansion of Hosting Foreign Students. The Ministry of Education and Human Resources Development.

Sandhu, D. S., \& Asrabadi, B. R. (1994). Development of an Acculturative Stress Scale for International Students: Preliminary Findings. Psychological reports, 75(1), 435-448.

Shin, J. C., Shin, T. S., \& Jung, J. S. (2008). Causal Relations between College Student Academic Achievement and Its Factors. The Journal of Educational Administration, 26(1), 287-313.

Strapp, C. M., \& Farr, R. J. (2010). To Get Involved or Not: The Relation among Extracurricular Involvement, Satisfaction, and Academic Achievement. Teaching of Psychology, 37(1), 5054.

Stoynoff, S. (1997). Factors Associated with International Students' Academic Achievement. Journal of Instructional Psychology, 24(1), 56-68.

Tamaoka, K., Ninomiya, A., \& Nakaya, A. (2003). What Makes International Students Satisfied with a Japanese University? Asia Pacific Education Review, 4(2), 119-128.

The Ministry of Education and the Korean Educational Development Institute. (2018). 2018 Brief Statistics on Korean Education. $\quad$ Retrieved from https://kess.kedi.re.kr/index
The University of Oxford. (2017). International Trends in Higher Education 2016-17. Oxford, England: The University of Oxford.

Tinto, V. (1997). Classrooms as Communities: Exploring the Educational Character of Student Persistence. The Journal of higher education, 68(6), 599-623.

Tinto, V. (1993), Leaving College: Rethinking the Causes and Cures of Student Attrition (2nd ed.). Chicago, IL: University of Chicago Press.

Turley, R. N. L., \& Wodtke, G., (2010). College Residence and Academic Performance: Who Benefits From Living on Campus? Urban Education, 45(4), 506-532.

Universities UK. (2018). The Financial Concerns of Students. National Education Opportunities Network, London.

Wan, T. Y., Chapman, D. W., \& Biggs, D. A. (1992). Academic Stress of International Students Attending U.S. Universities. Research in Higher Education, 33(5), 607-623.

Wang, Y. (2004). Pursuing Cross-cultural Graduate Education: A Multifaceted Investigation. International Education, 33(2), 52-72.

Wierzbicka, A. (1986). Does Language Reflect Culture? Evidence from Australian English. Language in Society, 15(3), 349-373.

Wimshurst, K., Bates, M., \& Wortley, R. (2006). The Impact of Institutional Factors on Student Academic Results: Implications for 'Quality' in Universities. Higher Education Research \& Development, 25(2), 131-145.

Yoo, M. B. (2012). An Introduction to Korean Public Administration ( $4^{\text {th }}$ ed.). Seoul, Korea: Bakyoungsa. 